Ис цитокинов у больных атопическим дерматитом

\author{
Е.Н. Волкова ${ }^{1}$, С.Г. Морозов², М.В. Тарасова', А.А. Григорьева ${ }^{3}$, И.В. Елистратова ${ }^{4}$
}

1 ГБОУ ВПО «Российский национальный исследовательский медицинский университет им. Н.И. Пирогова» Минздрава России

117997, Москва, ул. Островитянова, д. 1

2 ФГБУ «Научно-исследовательский институт общей патологии и патосризиологии» РАМН 125315, Москва, ул. Балтийская, д. 8

${ }^{3}$ ФГБУ «Государственный научный центр дерматовенерологии и косметологии» Минздрава России 107076, Москва, ул. Короленко, д. 3, стр. 6

${ }^{4}$ Центральный военный клинический госпиталь внутренних войск МВД России 143915, Московская обл., Балашиха, Вишняковское ш., вл. 101

\footnotetext{
Цель исследования. Изучение роли провоспалительных и противовоспалительных цитокинов в течении атопического дерматита.

Материал и методы. Обследованы 72 больных в в0зрасте 25-55 лет с атопическим дерматитом длительностью от 2 до 30 лет и наличием не менее двух рецидивов в год. В зависимости от величины индекса SCORAD (iSc) больные были разделены на группы: 1-я — с легкой фрормой (iSc < 30 баллов), 2-я — со среднетяжелой (iSc от 30 до 50 баллов), 3-я — с тяжелой (iSc > 50 баллов). В качестве контрольной группы обследовали 23 практически

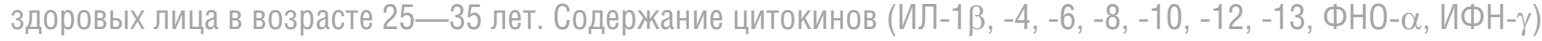
в сыворотке крови определяли методом иммуноферментного анализа.

Результаты. У больных атопическим дерматитом отмечена тенденция к повышенной продукции противовоспалительных цитокинов (ИЛ-4, -6, -10, -13) при обострении заболевания и повышению синтеза провоспалительных цитокинов (ИФН- $\gamma$, ФНО- $\alpha$, ИЛ-12) в период ремиссии, что свидетельствует о дисрегуляции реципрокных отношений Th1и Th2-субпопуляций лимфоцитов при данном заболевании.
}

Ключевые слова: цитокины, атопический дерматит.

Контактная инсрормация: volkovaen@cnikvi.ru. Вестник дерматологии и венерологии 2014; (2): 26—30. 


\title{
A study of the level of circulating cytokines in patients with atopic dermatitis
}

\author{
Ye.N. Volkova1', S.G. Morozov², M.V. Tarasova1, A.A. Grigoriyeva ${ }^{3}$, I.V. Yelistratova ${ }^{4}$
}

${ }^{1}$ The Russian National Research Medical University named after N.I. Pirogov (RNRMU)

Ostrovityanova str., 1, Moscow, 117997, Russia

${ }^{2}$ Federal State Budgetary Institution «Institute of General Pathology and Pathophysiology» under the Russian

Academy of Medical Sciences.

Baltiyskaya str., 8, Moscow, 125315, Russia

${ }^{3}$ State Research Center of Dermatovenereology and Cosmetology, Ministry of Healthcare of the Russian Federation Korolenko str., 3, bldg 6, Moscow, 107076, Russia

${ }^{4}$ Central Military Clinical Hospital Russian Interior Troops

Vishnjakovskoe sh., vl. 101, Balashikha, Moscow region, 143915, Russia

Goal of the study. To study the role of pro-inflammatory and anti-inflammatory cytokines for the course of atopic dermatitis (AD). Materials and methods. The study involved 72 patients aged $25-55$ suffering from atopic dermatitis for $2-30$ years and with at least two relapses a year. The AD patients were assigned to the following groups depending on the SCORAD (ISC) index: Group 1: light form (iSc < 30 points), Group 2: moderate to severe form (iSc from 30 to 50 points) and Group 3: severe form (iSc > 50 points). The control group comprised 23 practically healthy subjects aged 25-35. The level of cytokines (IL-1 $\beta,-4,-6,-8,-10$, $-12,-13$, TNF- $\alpha$ and IFN- $\gamma$ ) in blood serum was determined based on the immune-enzyme assay method.

Results. A trend to the increased production of anti-inflammatory cytokines (IL-4, -6, -10, -13) at the exacerbation stage and increased synthesis of pro-inflammatory ones (IFN- $\gamma$, TNF- $\alpha$ and IL-12) at the remission stage was observed in patients with atopic dermatitis, which confirms the dysregulation of reciprocal relationships between Th1 and Th2 lymphocyte subpopulations during the disease.

Key words: cytokines, atopic dermatitis.

Corresponding author: volkovaen@cnikvi.ru. Vestnik Dermatologii i Venerologii 2014; 2: 26_30.

Известно, что патогенез атопического дерматита (АД) связан с патологическими иммунными реакциями, медиаторами которых являются цитокины, инициирующие и поддерживающие воспалительный процесс в коже [1-5]. Показано, что при АД отмечаются иммунные нарушения регуляции функциональной активности Т-лимфоцитов, и в патогенез данного заболевания вовлечен ряд как провоспалительных, так и противовоспалительных цитокинов. Важным звеном в патогенезе этого заболевания является сдвиг Th1/Th2-цитокинового профиля в сторону Th2-реакций [6-9], который сопровождается повышенной секрецией $\mathrm{lgE}$. Даже в периоды внешнего благополучия в коже сохраняется Т-лимфоцитарная инфильтрация с усиленной продукцией цитокинов 2-го типа - интерлейкинов (ИЛ)-4 и -13. Дисрегуляцию соотношения Th1/Th2 связывают с генетической предрасположенностью [10-13].

В то же время нет единой точки зрения на значение ряда цитокинов, например фактора некроза опухоли (ФНО)- $\alpha$ и ИЛ-6, при различных клинических формах и стадиях АД. Имеющиеся в литературе данные о содержании различных цитокинов в сыворотке крови больных АД достаточно противоречивы [14-17].

Целью исследования явилось изучение роли провоспалительных и противовоспалительных цитокинов в течении АД.

\section{Материал и методы}

Изучено содержание ряда цитокинов у 72 больных АД с длительностью заболевания от 2 до 30 лет и наличием не менее двух рецидивов в год. Возраст больных колебался от 25 до 55 лет. В зависимости от величины индекса SCORAD (iSc) больные АД были разделены на группы: 1-я - 27 больных (10 женщин, 17 мужчин) с легкой степенью тяжести заболевания (iSc < 30 баллов, средний 21,4 \pm 2,1 балла), 2-я 31 больной (17 женщин, 14 мужчин) со среднетяжелой фрормой (iSc от 30 до 50 баллов, 40,4 \pm 3,7 балла), 3-я - 14 больных (9 женщин, 5 мужчин) с тяжелой формой (iSc > 50 баллов, 61,3 \pm 7,2 балла). В группы больных АД не включали пациентов с какой-либо со- 
матической патологией, в том числе с инфекционными, онкологическими, нервно-психическими и аутоиммунными заболеваниями. Контрольную группу составили 23 практически здоровых человека (10 мужчин, 13 женщин) в возрасте 25-35 лет.

Для определения содержания цитокинов в сыворотке крови из пальца или из вены получали образцы крови в сухие пластиковые пробирки. После обработки кровяного сгустка образец крови центрифугировали при 2500 g, отбирали с помощью пипетки сыворотку, которую использовали для анализа (сыворотку подвергали однократной заморозке при температуре от $-18{ }^{\circ} \mathrm{C}$ до $-24{ }^{\circ} \mathrm{C}$ и хранили до проведения анализа не более месяца).

Содержание цитокинов (ИЛ-1 $\beta,-4,-6,-8,-10,-13$, ФНО- $\alpha$, интерферона $(И Ф Н)-\gamma)$ в сыворотке крови определяли с помощью коммерческих иммуноферментных тест-систем производства Amersham (США). Для определения содержания ИЛ-12 применялись тест-системы фирмы R\&D (США). Содержание цитокинов в сыворотке крови больных АД определяли при обострении заболевания и после наступления ремиссии.

Обработку полученных данных осуществляли с использованием пакета стандартных программ Med star, версия 8.

\section{Результаты и обсуждение}

Известно, что одним из основных провоспалительных цитокинов является ИФН- $\gamma$, который продуцируется активированными Th1-лимфоцитами, макрофрагами и натуральными киллерами. Обнаружено, что содержание ИФН- $\gamma$ в сыворотке крови больных АД при средней степени тяжести и тяжелом течении заболевания отличалось от контрольных значений, причем в зависимости от фразы заболевания - обострение или ремиссия - изменения носили противоположный характер (табл. 1). При обострении болезни его уровень достоверно снижался, а во время ремиссии превышал контрольные значения, причем при средней степени тяжести заболевания достигал максимума.

Сходная картина наблюдалась при изучении содержания ИЛ-12, который оказывает стимулирующее влияние на формирование Th1-фенотипа при экспрессии его макрофрагами, дендроцитами и эозинофилами. Рецепторы ИЛ-12 содержатся только на Th1клетках и отсутствуют на Th2-лимфоцитах. Во всех обследуемых группах больных АД содержание ИЛ-12 достоверно возрастало лишь в период ремиссии, а во время обострения процесса достоверно не отличалось от данных контроля. При этом, как и в случае с ИФН- $\gamma$, максимальные значения его уровня наблюдались у пациентов во время ремиссии при среднетяжелой фор-

Таблица 1 Содержание цитокинов в сыворотке крови больных АД $(M \pm m)$

\begin{tabular}{|c|c|c|c|c|c|c|c|}
\hline \multirow{2}{*}{ Группа } & \multirow{2}{*}{$n$} & \multicolumn{2}{|c|}{ ИФН- $\gamma$} & \multicolumn{2}{|c|}{$\Phi \mathrm{HO}-\alpha$} & \multicolumn{2}{|c|}{ иЛ-1 $\beta$} \\
\hline & & обострение & ремиссия & обострение & ремиссия & обострение & ремиссия \\
\hline 1 & 27 & $26,5 \pm 5,4$ & $30,6 \pm 4,4^{\circ 2}$ & $42,1 \pm 2,8^{-2,3}$ & $59 \pm 5,0^{*} \square 3$ & $59 \pm 7,0^{\llcorner 2,3}$ & $59 \pm 7,8$ \\
\hline 2 & 31 & $21,2 \pm 3,0^{*}$ & $44,7 \pm 7,8^{*}$ & $52 \pm 4,3$ & $54 \pm 6,2^{* \square 3}$ & $75 \pm 9,5^{\text {* * }}$ & $55 \pm 5,8$ \\
\hline 3 & 14 & $21,0 \pm 3,1^{*}$ & $39,9 \pm 9,0^{*}$ & $60 \pm 6,7^{\star}$ & $76 \pm 9,4^{\star *}$ & $75 \pm 11,9^{\star \star \star}$ & $64 \pm 9,9$ \\
\hline 4 & 23 & & & & & & \\
\hline \multirow[t]{2}{*}{ Группа } & \multirow[t]{2}{*}{$n$} & \multicolumn{2}{|c|}{ ил-4 } & \multicolumn{2}{|c|}{ иЛ-6 } & \multicolumn{2}{|c|}{ ИЛ-10 } \\
\hline & & обострение & ремиссия & обострение & ремиссия & обострение & ремиссия \\
\hline 1 & 27 & $13 \pm 3,5^{\triangleright 2,3}$ & $13 \pm 4,8$ & $55 \pm 9,5^{\star \square 2,3}$ & $22 \pm 4,1^{\square 2,3}$ & $55 \pm 8,7^{* \square 3}$ & $45 \pm 5,0 \square \square$ \\
\hline 2 & 31 & $35 \pm 13,3^{* *}$ & $14 \pm 4,7$ & $76 \pm 14,0^{\star *}$ & $40 \pm 10,2^{*}$ & $56 \pm 7,0^{*}$ & $44 \pm 5,9 \square 3$ \\
\hline 3 & 14 & $39 \pm 11,9^{* *}$ & $14 \pm 3,7$ & $67 \pm 14,2^{* *}$ & $39 \pm 8,1^{*}$ & $70 \pm 13,2^{* *}$ & $67 \pm 11,3^{\text {* * }}$ \\
\hline 4 & 23 & & & & & & \\
\hline \multirow[t]{2}{*}{ Группа } & \multirow[t]{2}{*}{$n$} & \multicolumn{2}{|c|}{ ИЛ-12 } & \multicolumn{2}{|c|}{ иЛ-8 } & \multicolumn{2}{|c|}{ иЛ-13 } \\
\hline & & обострение & ремиссия & обострение & ремиссия & обострение & ремиссия \\
\hline 1 & 27 & $31 \pm 3,9$ & $47 \pm 7,7^{* \square 2}$ & $79 \pm 12,4^{\star \star}$ & $65 \pm 9,8$ & $48 \pm 7,3^{* \square 3}$ & $34 \pm 4,9 \square \square$ \\
\hline 2 & 31 & $41 \pm 7,0$ & $67 \pm 14,6^{* *}$ & $71 \pm 14,3^{\text {** }}$ & $64 \pm 12,0$ & $48 \pm 8,5^{\star \triangleright \square}$ & $37 \pm 9,9 \square 3$ \\
\hline 3 & 14 & $39 \pm 6,8$ & $60 \pm 14,1^{\text {** }}$ & $86 \pm 16,2^{* *}$ & $76 \pm 7,7^{\star *}$ & $71 \pm 10,1^{* *}$ & $69 \pm 8,0^{* *}$ \\
\hline
\end{tabular}

Примечание. * $-p<0,05 ;{ }^{* *}-p<0,01$ по сравнению с контрольной группой (группа 4); ${ }^{* 3}-p<0,05$ по сравнению c группой 3 ; 口а2 $-p<0,01$ по сравнению с группой 2; ${ }^{\circ 3}-p<0,01$ по сравнению с группой $3 ;{ }^{\circ 2}-p<0,05$ по сравнению с группой 2. 
ме заболевания. В настоящее время доказано, что клетки, имеющие френотип Th1, под действием ИЛ-12 начинают продуцировать ИФН- $\gamma$ и вызывают повреждение кератиноцитов. Причиной индукции ИФН- $\gamma-$ зависимых реакций может быть влияние разных микробных антигенов и суперантигенов. К гуморальным фракторам среды, подавляющим синтез ИФН- $\gamma$, относят прежде всего ИЛ-10 и простагландин $\mathrm{E}_{2}$.

Изменения сывороточного содержания провоспалительного цитокина ФНО- $\alpha$ не носили столь определенного и выраженного характера в зависимости от стадии процесса. Достоверное увеличение его уровня наблюдалось при тяжелом течении АД как при обострении болезни, так и во время ремиссии, а также во время ремиссии у больных со среднетяжелым течением заболевания. При легком течении АД его уровень не отличался от контрольных значений.

ИЛ-1 $\beta$ относят к провоспалительным цитокинам, так как он выступает в качестве одного из главных медиаторов, ответственных за формирование местной воспалительной реакции и острофазного ответа при инфекционном поражении. Однако следует иметь в виду, что одним из главных механизмов его действия является индукция синтеза ИЛ-2 и ИЛ-4. Кроме того, ИЛ-1 $\beta$ усиливает экспрессию рецепторов к ИЛ-2 и ИЛ-4, что создает условия для аутокринной регуляции пролиферации Т-хелперов. Наибольшая стимулирующая активность ИЛ-1 $\beta$ связана с теми Т-хелперами, которые продуцируют ИЛ-4, т. е. Th2. Вероятно, этим и объясняется достоверное повышение его содержания в сыворотке крови больных АД во время обострения при тяжелом и среднетяжелом течении заболевания. При разрешении клинических проявлений болезни значимые изменения уровня ИЛ-4 отсутствовали.

Изменения содержания противовоспалительных цитокинов ИЛ-4, -6, -10 и -13 во многом были схожи. Степень их высвобождения во многом зависела от распространенности и тяжести процесса при АД. Наибольшие их концентрации отмечались во время обострения при тяжелом и среднетяжелом течении заболевания.

Следует отметить, что ИЛ-4 и ИФН- $\gamma$ являются ключевыми цитокинами, определяющими путь дальнейшей дифференцировки наивных CD4+ Т-клеток. Показано, что при отсутствии гена, кодирующего ИФН- $\gamma$, нарушается иммунный ответ по клеточному типу, поддерживаемый Th1-лимфоцитами, а элиминация ИЛ-4 блокирует Th2-зависимый ответ. Диффреренцировка наивных CD4+ Т-клеток в направлении Th2 приводит к синтезу цитокинов ИЛ-4, -10, которые подавляют активность ИЛ-12, а также ИЛ-1 $\beta$, которые могут индуцировать рецепторы и синтез Т-клетками ИЛ-2 и ИФН-ү. Таким образом, ИЛ-4 подавляет образование Th1-цитокинов, сдвигая баланс Th1 и Th2 в сторону Th2.

Как известно, Th1- и Th2-субпопуляции лимфоцитов находятся в реципрокных отношениях, и, продуцируя противоположные по эффекту цитокины, каждая из субпопуляций подавляет дифференцировку полярной группы, тем самым снижая продукцию альтернативных цитокинов. Такие реципрокные отношения субпопуляций цитокинов наглядно прослеживаются при комплексном анализе полученных результатов у пациентов с АД. Наблюдающаяся тенденция к повышению уровня ИЛ-4, -6, -10 и -13 в период обострения может свидетельствовать о подавлении функциональной активности Th1-звена иммунитета на фоне повышения функциональной активности Th2-лимфоцитов. Во время ремиссии наблюдается обратная картина - увеличение содержания в сыворотке провоспалительных цитокинов - ИФН- $\gamma$, ФНО- $\alpha$, ИЛ-12, что свидетельствует о повышении функциональной активности Th1-лимороцитов. В целом все эти данные косвенно демонстрируют дисбаланс этих субпопуляций Т-хелперов при АД.

Выделяют разные причины, обусловливающие сдвиг иммунных реакций в сторону Th2-звена при АД. Прежде всего это наследственные фракторы. Так, известно около 20 генов, ассоциируемых с предрасположенностью к атопии. Особый интерес заслуживает область на 5-й хромосоме (5q31-33), содержащая кластер генов, которые кодируют цитокины, характеризующие Th2-профиль: ИЛ-3, -4, -5, -13. Установлены ассоциации аллергических заболеваний с участком этого кластера, кодирующим ИЛ-4. Полиморфизм по промотору ИЛ-4 связан с высоким содержанием IgE. Кроме того, большое значение имеют местные фракторы, обусловливающие диффреренцировку Th0-клеток в Th2. В число этих факторов входят цитокиновое окружение, тип антигена и костимуляции, воздействие разных гуморальных компонентов. Моноциты больных АД отличаются повышенной активностью цАМФфоссфодиэстеразы, способствующей продукции ИЛ-4, -10 , простагландина $\mathrm{E}_{2}$ и $\lg \mathrm{E}$.

\section{Коэфффициент корреляции между индек- \\ Таблица 2 com SCORAD и содержанием цитокинов в сыворотке крови больных АД}

\begin{tabular}{lc}
\hline Показатель & SCORAD \\
\hline ИФН- $\gamma$ & $-0,07$ \\
\hline ФН0- $\alpha$ & $0,44^{*}$ \\
\hline иЛ-1 $\beta$ & 0,23 \\
\hline ИЛ-4 & $0,51^{*}$ \\
\hline ИЛ-6 & 0,04 \\
\hline ИЛ-10 & 0,39 \\
\hline ИЛ-12 & 0,05 \\
\hline ИЛ-8 & 0,02 \\
\hline ИЛ-13 & 0,30 \\
\hline
\end{tabular}

Примечание. ${ }^{*}-p<0,05$. 
Что касается содержания в сыворотке ИЛ-8, то его уровень был повышен по сравнению с контролем в разных группах в 64-79\% образцов и незначительно зависел от клинической картины заболевания, несмотря на то что основным его свойством является обеспечение хемотаксиса в зону воспаления различных типов клеток - нейтрофилов, моноцитов, эозинофилов, Т-лимфоцитов.

Определены коэффрициенты корреляции между величиной индекса SCORAD и уровнем цитокинов во время обострения АД (табл. 2). Обнаружено, что только уровень ФНО- $\alpha$ и ИЛ-4 достоверно коррелировал с тяжестью заболевания с учетом индекса SCORAD. Heсмотря на то что повышение уровня ФНО- $\alpha$ было более характерно для ремиссии, во время обострения заболевания он также коррелировал с тяжестью болезни.

\section{Заключение}

Подводя итог проведенному исследованию содержания цитокинов в сыворотке крови у пациентов с АД различной степени тяжести, можно сделать вывод о том, что прослеживается тенденция к повышенной продукции противовоспалительных цитокинов (ИЛ-4, -6, -10, -13) при обострении заболевания и повышению синтеза провоспалительных цитокинов (ИФН- $\gamma$, ФНО- $\alpha$, ИЛ-12) во время ремиссии, что свидетельствует о дисбалансе субпопуляций Th1 и Th2 лимфоцитов при АД. І

\section{Литература}

1. Kozlova V.A., Sennikov S.V. Sistema tsitokinov: teoreticheskie i klinicheskie aspekty. Novosibirsk: Nauka 2004; 324. [Козлова В.А., Сенников С.В. Система цитокинов: теоретические и клинические аспекты. Новосибирск: Наука 2004; 324.]

2. Revyakina V.L., Korostovtsev D.S., Dygylova N.D. Atopic dermatitis: role of cytokines. Allergology 2000; 1: 40—47. [Ревякина В.Л., Коростовцев Д.С., Дигилова Н.Д. Атопический дерматит: роль цитокинов в механизмах развития. Аллергология 2000; (1): 40-47.]

3. Simbirtsev A.S. Cytokines - classification and biologic functions. Cytokines \& inflammation 2004; 3 (2): 16-22. [Симбирцев А.С. Цитокины: классификация и биологические функции. Цитокины и воспаление 2004; 3 (2): 16-22].

4. Eichenfield L.F, Ellis C.N., Mancini A.J. et al. Atopic dermatitis: epidemiology and pathogenesis update. Semin Cutan Med Surg 2012; 31 (3): 3-5.

5. Noh G, Lee J. Atopic dermatitis and cytokines: the immunoregulatory and therapeutic implications of cytokines in atopic dermatitis--part II: negative regulation and cytokine therapy in atopic dermatitis. Recent Pat Inflamm Allergy Drug Discov 2012; 6 (3): 248—261.
6. Ketlinskiy S.A. Rol' T-khelperov tipov 1 i 2 v regulyatsii kletochnogo i gumoral'nogo immuniteta. Immunologiya 2002; 2: 77-79. [Кетлинский С.А. Роль Т-хелперов типов 1 и 2 в регуляции клеточного и гуморального иммунитета. Иммунология 2002; (2): 77-79.]

7. Akdis M., Blaser K., Akdis C.A. T regulatory cells in allergy. Chem Immunol Allergy 2006; 91: 159—173.

8. Akdis M., Blaser K., Akdis C.A. T regulatory cells in allergy: novel concepts in the pathogenesis, prevention, and treatment of allergic diseases. J Allergy Clin Immunol 2005; 116 (5): 961—968.

9. Grewe M., Bruijnzeel-Koomen C.A., Schopf E. et al. A role for Th1 and Th2 cells in the immunopathogenesis of atopic dermatitis. Immunol Today 1998; 19: 359-361.

10. Allam J.P., Novak N. The pathophysiology of atopic eczema. Clin Exp Dermatol 2006; 31: I 89—93.

11. Bacchetta R., Gregori S., Roncarolo M.G. CD4+ regulatory T cells: mechanisms of induction and effector function. Autoimmun Rev 2005; 4 (8): 491— 496.
12. Braathen L.R. T-cells subsets in patients with mild and severe atopic dermatitis. Acta Derm Venereol 1985; 114: $55-60$.

13. Ohshima Y., Yasutomi M., Omata N. et al. Dysregulation of IL-13 production by cord blood CD4+ T cells is associated with the subsequent development of atopic disease in infants. Pediatr Res 2002; 51 (2): 195-200.

14. Berke R., Singh A., Guralnick M. Atopic dermatitis: an overview. J Am Fam Phys 2012; 186 (1): 35—42.

15. Lee J., Noh G., Lee S. et al. Atopic dermatitis and cytokines: recent patents in immunoregulatory and therapeutic implications of cytokines in atopic dermatitis--part l: cytokines in atopic dermatitis. Recent Pat Inflamm Allergy Drug Discov 2012; 6 (3): 222—247.

16. Leung D.Y. Immunopathogenesis of atopic dermatitis. Immunol Allergy Clin North Am 2002; 22: 73—90.

17. Machura E., Mazur B., Kwiecien J., Karczewska K. Intracellular production of IL-2, IL-4, IFN-gamma, and TNF-alpha by peripheral blood CD3(+) and CD4 (+) T cells in children with atopic dermatitis. Eur J Pediatr 2007; 166 (8): 789-795

об авторах:

Е.Н. Волкова - д.м.Н., профессор кафредры дерматовенерологии лечебного факультета ГБОУ ВПО «РНИМУ им. Н.И. Пирогова» Минздрава России, Москва

С.Г. Морозов - д.м.Н., член-корр. РАМН, профессор, зам. директора по научной работе ФГБУ «НИИ Общей патологии и патофизиологии» РАМН, Москва

М.В. Тарасова — ассистент кафедры дерматовенерологии лечебного факультета ГБОУ ВПО «РНИМУ им. Н.И. Пирогова» Минздрава России, Москва

А.А. Григорьева — научный сотрудник ФГБУ «ГНЦДК» Минздрава России, Москва

И.В. Елистратова — к.м.н., врач-дерматовенеролог ЦВКГ ВВ МВД России, Балашиха

\section{Конфликт интересов}

Авторы заявляют об отсутствии потенциального конфрликта интересов, требующего раскрытия в данной статье 